Publisher: VIEWEG, ABRAHAM-LINCOLN-STRABE 46, POSTFACH 15 47, D-65005 WIESBADEN, GERMANY

Subject Category: Biochemical Research Methods; Chemistry, Analytical

IDS Number: 660RA

ISSN: 0009-5893

http://www.springerlink.com/content/u472k433j35I67t7/

\title{
EXTRACTION OF WOOD COMPOUNDS BY USE OF SUBCRITICAL FLUIDS
}

\section{J. González-Rodríguez ${ }^{1}$ P. Pérez-Juan ${ }^{1}$ / M.D. Luque de Castro ${ }^{2, *}$}

${ }^{1}$ R\&D Department Pérez Barquero, S.A. Avda. de Andalucía, 27, 14550 Montilla, Córdoba, Spain. E-mail: barquero@fiab.es

2 Department of Analytical Chemistry, University of Córdoba, Campus of Rabanales, Annex C-3, 14071 Córdoba, Spain. E-mail: qa1lucam@uco.es

A study of the extraction of oak wood compounds with subcritical water-ethanol mixtures as extractant, with an ethanol content between $0-60 \%$, is reported. Identification and characterisation of the extracted compounds have been made by spectrophotometry and gas chromatography with either flame ionisation or mass detectors. Extraction was performed statically manner by use of a single cycle or repeated cycles. All variables affecting the extraction process were studied and optimised. Extraction time and temperature are $60 \mathrm{~min}$ and $200^{\circ} \mathrm{C}$, respectively. Comparison of the extract thus obtained with commercial extracts showed the former to be rich in compounds characteristic of the commercial extracts. The method enables manipulation of the extract composition by changing the temperature and water/ethanol ratio used. It is faster than the traditional procedures for obtaining wood extracts.

Keywords: gas chromatography-mass spectrometry, solid-liquid extraction, subcritical fluids, oak wood. 


\section{Introduction}

The ageing of alcohol beverages is traditionally performed using oak wood barrels as the extraction of key compounds from the wood produces desirable changes in the composition of wines or spirits. Oak wood is mainly composed of three large insoluble polymers, cellulose, hemicellulose and lignin but it also contains different compounds with lower molecular weight such as volatile and non-volatile acids, sugars, steroids, terpenes, volatile phenols, lactones, etc. [1-3], which can be extracted by ethanol-water mixtures in very different ratios depending on the alcohol content of the extractant. The heating and charring operations made during the manufacture of oak wood barrels modify the macromolecular structure of wood, giving place to a degradation of polysaccharides and polyphenols and to the appearance of new classes of volatile substances such as pyrazines, furans, phenols, etc. Several studies have demonstrated changes in the composition of oak when it is toasted over a wood fire [4,5]. Small amounts of hundreds of volatile compounds can be found in non toasted oak wood [6]; meanwhile relative few volatile compounds including vanillin, eugenol, and cis-and trans- $\beta$-methyl- $\gamma$ octalactones are present in significant amounts $[2,7,8]$. Other volatile compounds are formed by thermal degradation of the main wood polymers during the toasting process but also the amounts of the compounds found in untoasted oak wood increase by the toasting step. Phenol and furan aldehydes are the most abundant aromatic compounds identified in toasted wood; however, only vanillin contributes actively to aroma. A number of other volatile phenols responsible for the "spicy" and "smoky" characteristics of toasted wood [5] are formed during this step.

Extracts obtained from toasted or non toasted wood, containing different amount of these wood compounds, have been traditionally used for modifying the colour and flavour of alcohol beverages. The composition of these wood extracts is under European Legislation [9] and must be performed using exclusively alcohol and water. Extracts of fragrance and flavour substances obtained from plants are known as pomades, concentrates, absolutes, resinoids, or tinctures, according to the method used for preparation. Industrial manufacture of wood extracts is performed by treating natural raw material with ethanol or water-ethanol mixtures, thus obtaining a tincture [10]. Comercial wood extracts are obtained by recirculating water/ethanol mixtures through a bed of chips at ambient temperature and pressure for 4 to 7 hours, although the specific details are considered a trade secret. Solvent extraction is generally applied for the separation of thermolabile plant compounds.

The use of water under certain conditions (subcritical water) for the extraction of essential oils from aromatic plants is a recent [11,12] and 
very promising field which has promoted the development of an alternative method different from the conventional method used so far for obtaining aromatic compounds from wood.

\section{Experimental}

\section{Instruments and Apparatus}

The subcritical fluid extractions were performed using the following assembly: a Knauer 64 high pressure pump (Knauer, Berlin, Germany), used to propel the extractant liquid through the system. The extractor, depicted in Figure 1, consisted of a stainless steel cylindrical extraction chamber (150 x11 $\mathrm{mm}$ i.d., $14 \mathrm{~mL}$ internal volume) which was closed with screws at both ends in order to permit its filling with extractant and emptying of the extract. The screw caps also contained stainless steel filters plates $(2 \mathrm{~mm}$ in thickness and $6,35 \mathrm{~mm}$ in i.d.) to ensure that the wood chips remained in the extraction chamber. This chamber, together with a stainless steel preheater, was located in a gas chromatograph oven (HP 5720A, Hewlett-Packard, Wilmington, DE) used as heating source and designed to work up to $400{ }^{\circ} \mathrm{C}$. A loop made from 1-m length stainless-steel tubing, and cooled with water at room temperature, was used to cool the extract from the oven to a temperature close to $25{ }^{\circ} \mathrm{C}$. A pressure needle valve coupled to the outlet of the cooler, and a selecting valve located between the high-pressure pump and the oven allows flush the extract with $\mathrm{N}_{2}$ after extraction.

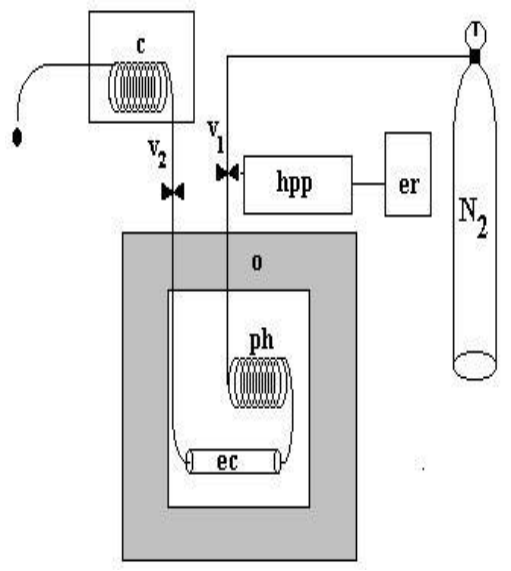

Figure 1. Extraction System. hpp: high pressure pump, er: extractant reservoir, ph: pre-heater, ec: extraction cell, o: oven, c: cooler, $\mathrm{v}_{1}=$ selection valve, $\mathrm{v}_{2}=$ restriction valve.

Analysis of the extracts were performed using a Varian 3900 gas chromatograph equipped with a Chrompack capillary CP-Wax 57 CB fused silica column $(50 \mathrm{~m} \times 0.25 \mathrm{~mm}$ id, $0.2 \mu \mathrm{m}$ film thickness) and a flame ionisation detector (FID). Finally, a Saturn 2200 mass spectrometer (Varian) equipped with a Chrompack capillary CP-Sil 8 CB fused silica column (50 m x $0.25 \mathrm{~mm}$ i.d.) was used to characterise the compounds. A Cary 50 Conc spectrophotometer from Varian (Mulgrave, Australia), connected to a computer with Cary WinUV v.2.0 ${ }^{\circledR}$ (Varian) software for data collection and treatment, was also used for total polyphenol index (t.p.i.) measurements of the extracts. 
All the extracts were centrifuged using a Selecta (Barcelona, Spain) Mixtasel centrifuge and filtered using $0.45 \mu \mathrm{m}$ Minisart filters from Sartorius (Göttingen, Germany). Statistical treatments were made using Statgraphics ${ }^{\mathrm{TM}}$ plus 2.1. for Windows.

\section{Reagents}

Wood chips of American oak were obtained from a barrel shop in Montilla (Córdoba, Spain). Ethanol 96\% ( $v / v$ ) PA from Panreac (Barcelona, Spain) and distilled water were used for preparing the water-alcohol extraction mixtures used with ethanol contents from 0 to $60 \%$. All gases were of $95 \%$ purity or higher (Air Liquide, Paris, France).

\section{Procedures}

\section{Subcritical Extraction}

The sample cell in Figure 1 was filled with $1.5 \mathrm{~g}$ of wood chips, and two pieces of paper Albet 235 were inserted at both ends of the cell to prevent frit from clogging. After assembling the extraction cell in the oven, this was brought up to the working temperature $\left(200{ }^{\circ} \mathrm{C}\right)$ and pressurised up to $40 \mathrm{~atm}$ with a water-alcohol mixture, maintaining closed valve $v_{2}$. Once the system was pressurised, valve $\mathrm{v}_{1}$ was closed, and a static extraction was developed for $60 \mathrm{~min}$. After this, $\mathrm{v}_{1}$ was switched to the open position to allow nitrogen to flow through the cell by opening valve $v_{2}$. Then, the extract was collected in a vial at room temperature.

\section{Chromatographic Separation and Detection}

For the optimisation study $2-\mu \mathrm{L}$ aliquots of extract were injected into the chromatograph in the (1:15) split mode. The flow-rate of the carrier gas (helium) was $2.2 \mathrm{~mL} \mathrm{~min}^{-1}$; the injector and detector temperatures were programmed at $270{ }^{\circ} \mathrm{C}$; the oven temperature program was: $40{ }^{\circ} \mathrm{C}(10 \mathrm{~min})$, $40{ }^{\circ} \mathrm{C}$ to $200{ }^{\circ} \mathrm{C}\left(15^{\circ} \mathrm{C} \mathrm{min}^{-1}\right), 200{ }^{\circ} \mathrm{C}$ (90 min).

For characterisation of the extract, an aliquot of $1 \mu \mathrm{L}$ of extract was injected in the chromatograph/mass spectrometer in the 1:15 split mode. The carrier gas (helium) flow-rate was $1 \mathrm{~mL} \mathrm{~min}^{-1}$; injector and detector temperatures were programmed at 270 and $300{ }^{\circ} \mathrm{C}$, respectively; the oven temperature program was: $40{ }^{\circ} \mathrm{C}(10 \mathrm{~min}), 40$ ${ }^{\circ} \mathrm{C}$ to $200{ }^{\circ} \mathrm{C}\left(15^{\circ} \mathrm{C} \min ^{-1}\right), 200{ }^{\circ} \mathrm{C}(20$ $\min ), 200^{\circ} \mathrm{C}$ to $275^{\circ} \mathrm{C}\left(10^{\circ} \mathrm{C} \mathrm{min}^{-1}\right)$.

\section{Determination of the Total Polyphenol Index $\left(I_{280}\right)$}

The extracts were diluted with water in an 1:100 ratio and the absorbance was directly monitored at $280 \mathrm{~nm}$. The value of the $I_{280}$ was calculated by multiplying the absorbance $\mathrm{x} 100$.

\section{Results and Discussion}

A static approach was tested for the extraction of compounds from wood in order to enhance the sample-extractant contact, thus favouring the attainment of the partition equilibrium. 


\section{Optimisation of Variables}

The variables affecting subcritical extraction were studied in order to maximise the yield of compounds extracted from wood in a time as short as possible. With this aim, a multivariate approach was used for optimising the physical variables affecting the extraction, and a univariate approach was used for studying influence of the ethanol percent in the extraction mixture. The range over which the variables were studied and the optimum values found are given in Table I.

A multivariate approach was used for the optimisation of the extraction time and temperature within the ranges 10-75 min and $80-300{ }^{\circ} \mathrm{C}$, respectively, using the areas or eight of the peaks chosen from the GC-FID chromatograms as dependent variable. The results from the ANOVA studies and the response surfaces for the experimental design obtained were statistically equal in all cases.

The signal increased when time and temperature were increased but with a higher effect from the former. A time of $60 \mathrm{~min}$ and a temperature of $200{ }^{\circ} \mathrm{C}$ were selected as optimum. Temperatures higher than $200{ }^{\circ} \mathrm{C}$ caused degradation of a number of the compounds characteristic of the wood extracts, as shown in the GC-FID chromatogram in Figure 2. The extracts obtained at these temperatures (Figure 2(b)) had a strong wood burning smell instead of that typical of toasted wood. The characteristic structure was lost in the process. These reasons made that these temperatures were rejected despite some of the peaks selected for the optimisation study increased. Since the P-value in the ANOVA table is less than $0.05 \%$, there is a statistically significant relationship between the variables at $95 \%$ confidence level. The equation of the model for the chosen peak is: Area $=2727-194.6 T+251 t+$ $1.5 T^{2}+2,3 T t-3.8 t^{2}$, where $T=$ temperature and $t=$ time.

Table I. Results of the optimisation study

\begin{tabular}{lll}
\hline Variable & $\begin{array}{l}\text { Tested } \\
\text { range }\end{array}$ & $\begin{array}{l}\text { Optimum } \\
\text { value }\end{array}$ \\
\hline $\begin{array}{lll}\text { Chemical } \\
\text { EtOH }(\% \mathrm{v} / \mathrm{v})\end{array}$ & $0-60$ & 60 \\
$\begin{array}{l}\text { Physical } \\
\begin{array}{l}\text { Extraction time } \\
(\text { min })\end{array}\end{array}$ & $10-75$ & 60 \\
$\begin{array}{l}\text { Extraction } \\
\text { temperature }\left({ }^{\circ} \mathrm{C}\right)\end{array}$ & $80-300$ & 200 \\
$\begin{array}{l}\text { Sample weight }(\mathrm{g}) \\
\text { Pressure (atm) }\end{array}$ & - & 1.5 \\
\hline
\end{tabular}

The amount of ethanol in the extractant was studied by the univariate method in the range $0-60 \%(v / v)$. Higher concentrations were not used because $60 \%(v / v)$ ethanol is the maximum found both in the literature and commercial extracts. It was found that maximum extraction of the target compounds was achieved by increasing the ethanol concentration. Between the ethanol-water mixtures assayed, that with $60 \%$ of ethanol provided the 


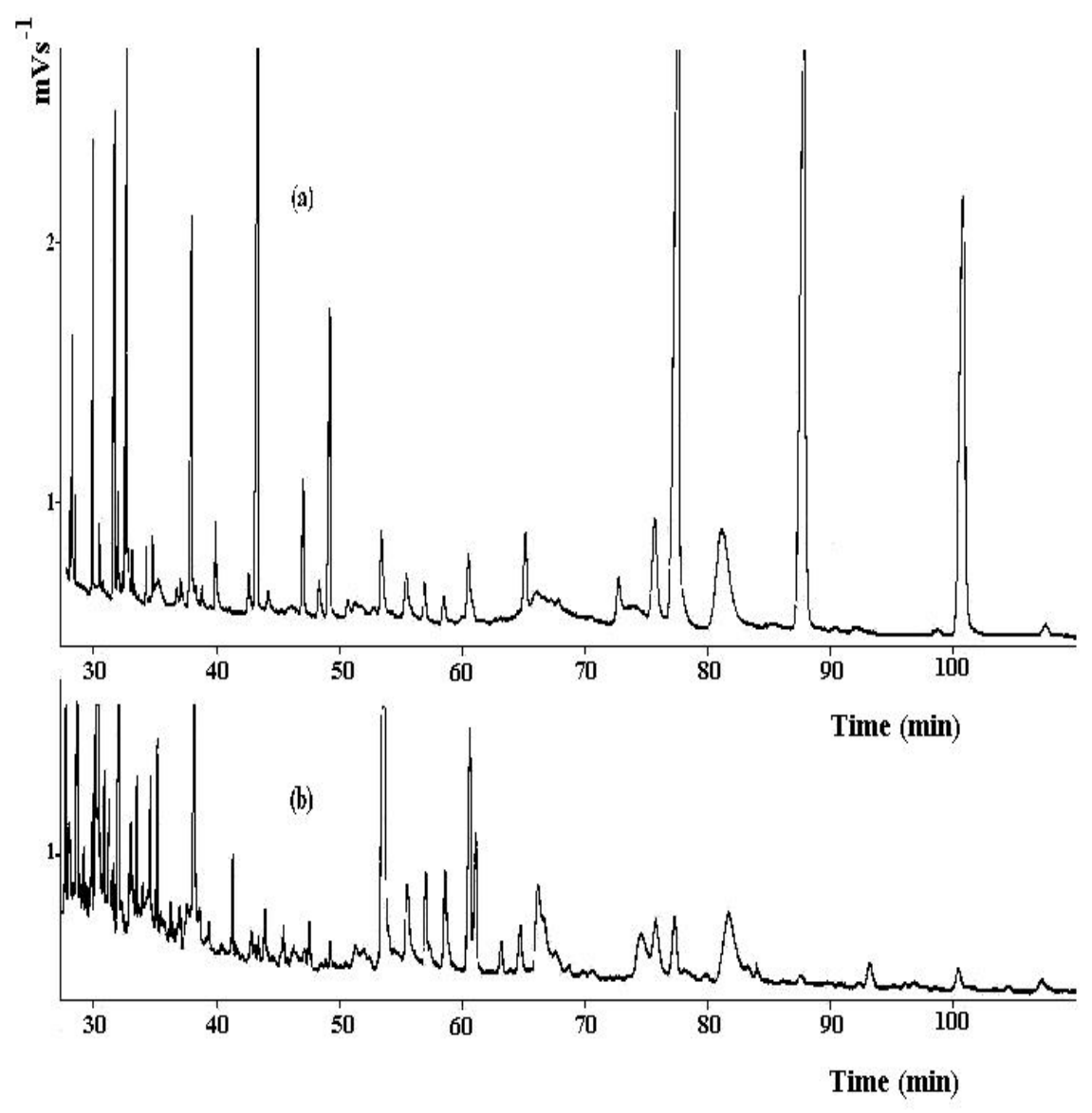

Figure 2. GC-FID chromatograms of extracts from wood. Study of degradation with temperature at $200{ }^{\circ} \mathrm{C}$ (a) $300{ }^{\circ} \mathrm{C}$ (b). 
extract with maximum concentration of the compounds which are be found in the commercial product.

The amount of sample used was that necessary $(1.5 \mathrm{~g})$ to fill the extraction cell. The pressure was that required to maintain liquid the ethanolwater mixture. As the vapour pressure of ethanol and water at the optimum temperature $\left(200^{\circ} \mathrm{C}\right)$ are 30 and $20 \mathrm{~atm}$, respectively, [13], a pressure of $40 \mathrm{~atm}$ was chosen in order to guarantee the liquid state of the extractant in all the experiments.

\section{Composition of the Extract}

The composition of the extract obtained using the optimal working conditions was characterised by gas chromatography-mass spectrometry in Total Ion Count (TIC) mode, that provided the chromatogram shown in Figure 3(a); which was compared with that in Figure 3(b), which corresponds to the commercial product more similar to that provided by the proposed method. Approximately $75 \%$ of the compounds found in the commercial product are present in the extract obtained by the proposed method, and $50 \%$ of the compounds present in both are those typically found in the literature as characteristic of extracts from oak wood.

Although more than 140 compounds have been found in the extract from oak wood [14-17], only approximately 25 can be considered typical of this wood. The heterogeneity is quite common because the composition depends on the storage, origin, specie, and seasoning of the oak wood used for the study. Commercial extracts are widely available but the specific nature of the wood, its preparation, and the extraction procedures used to obtain them is considered a trade secret. Thus, these commercial extracts can only be used for rough comparisons.

As can be observed in Figure 4, by comparing the chromatogram obtained by GC-FID from the extract provided by the proposed method with those from commercial products used in the study, the former shows similar composition to the latter, then the extract provided by the proposed method is not inconsistent with the commercial products. The same conclusion is obtained through the total polyphenol index (t.p.i.) as a measurement of the polyphenol content of the extract. Figure 5 shows the t.p.i. obtained for the six commercial extracts analysed and the t.p.i. of the subcritical extracts obtained by using different ethanolwater mixtures, compared with the average value obtained for the commercial products (represented by the dotted line). The t.p.i. value increases with growing concentrations of ethanol in the extractant. Thus, for a concentration of $20 \%(v / v)$ ethanol, the t.p.i. of the subcritical extract is higher than that obtained from the commercial average with an ethanol content of $50 \%(\mathrm{v} / \mathrm{v})$, approximately.

\section{Exhaustive Extraction}

A study of exhaustive extraction of the valuable compounds in the wood sample was performed. Table II shows 


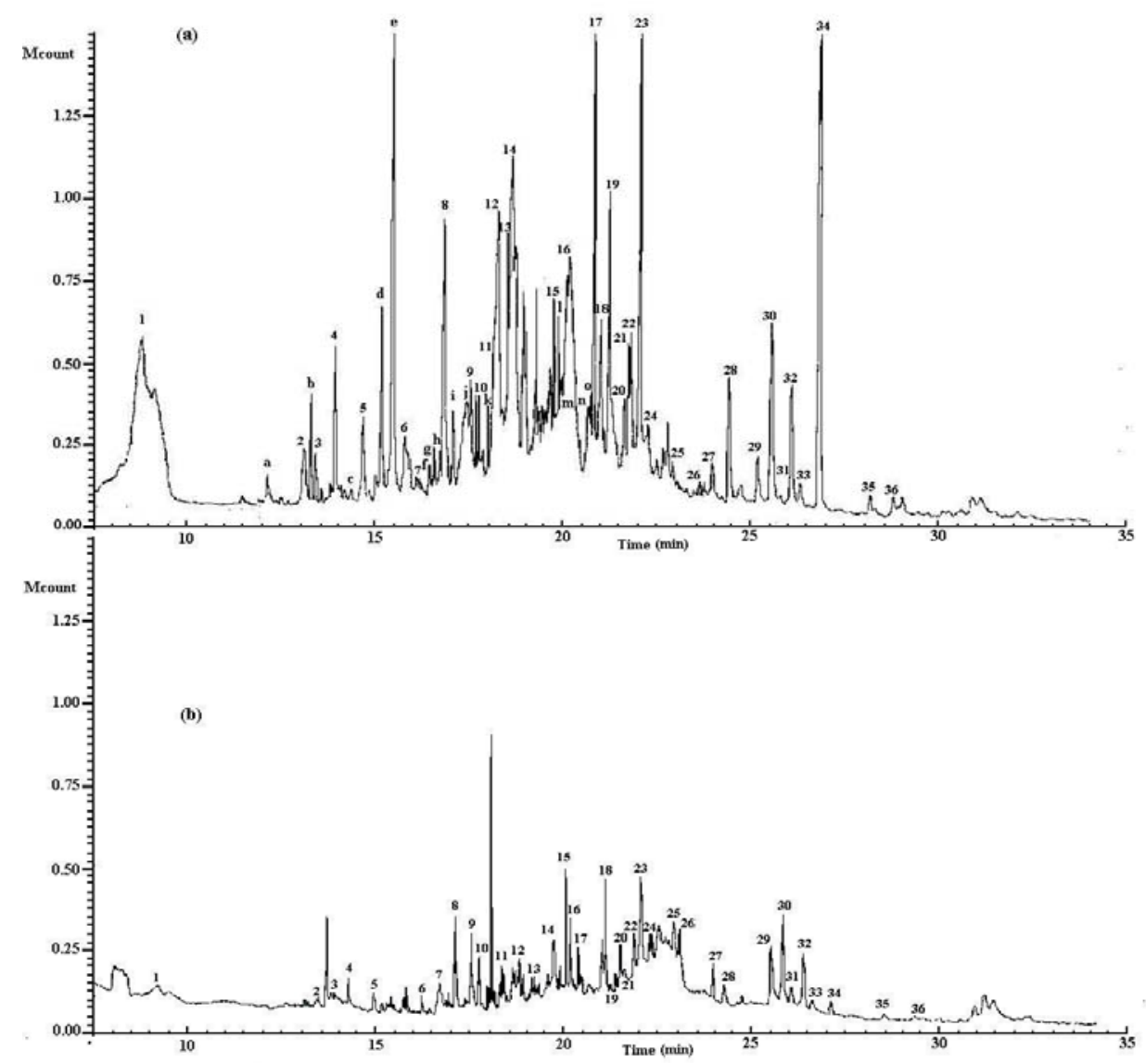

Figure 3. GC-MS chromatograms TIC mode of (a) a subcritical extract (b) a commercial extract (C3). Compounds common to both chromatograms are as follows: $\mathbf{1 = F u r f u r a l ; ~} 2=5$ metil furfural; 3=Silicone; 4=Dipropyl succinate; 5=Dimethyl succinate; 6=5-metyl hedantoin; 7=Ciclohexenone; $\mathbf{8}=$ Hydroxymethyl furfural; 9=Octanoic acid; $\mathbf{1 0}=\mathrm{p}$-vinyl guaiacol; 11=Syringol; 12=Eugenol; 13=Decanoic acid; 14=Vanillin; 15=Ethyl- $\beta$-riboside; 16=Ionol; 17=Buthyl hydroxy anisol; 18=Syringaldehyde; 19=4-hydroxy- $\beta$-ionone; $\mathbf{2 0}=$ Ferulic acid; 21=Coniferaldehyde; 22=Methyl homovanillate; 23=p-methoxycinamic acid; 24=2,4-dimethoxycinamic acid; 25=5-hydroxyveratric acid; 26=Acetosinryngone; 27=Homosyringic acid; 28=2,3,5-trimethoxycinamic acid; $\mathbf{2 9 = P a l m i t i c ~ a c i d ; ~} \mathbf{3 0}=2,3,4$ trimethoxyphenylacetic acid; 31=p-cumarine; 32=3,4-dimethoxycinamic acid; 33=3,5dimethoxy-hydroxy-cinamaldehyde; $\quad 34=2,3,4$-trimethoxycinamic $\quad$ acid; $\quad 35=2,3,4-$ trimethoxyphenylpropanoic acid; 36=3,5-ditercbuthylcathecol. Compounds found only in the extract from the proposed method. $\mathbf{a}=1,2$-ciclopentanodione; $\mathbf{b}=$ Acriloil urea; $\mathbf{c}=$ Methylciclopentanolone; $\mathbf{d}=$ =Pimelic acid; $\mathbf{e}=$ Ciclohexenone; $\mathbf{f}=$ Methyl succinate; $\mathbf{g}=$ Dodecanal; $\mathbf{h}=4$-hexanoic acid; $\mathbf{i}=$ =Methyl-3-hydroxy-hexanoate; $\mathbf{j}=$ =Glucose; $\mathbf{k}=$ Dodecalactone; l=Isoeugenol; m=Galacto-heptulose; $\mathbf{n}=\delta$-glycero-l-glucoheptose; $\mathbf{o}=2,5$-diethoxyphenol. 
the t.p.i. values obtained using the extractant solutions with 10 and $60 \%$ ethanol.

Similar percentages of polyphenols were extracted in a given cycle which respect to the overall amount obtained.
Using the average commercial value for comparison (t.p.i. $=201$ in Figure 5) it can be observed that only in the case of $60 \%$ ethanol higher values than 201 were obtained for cycle 2 .

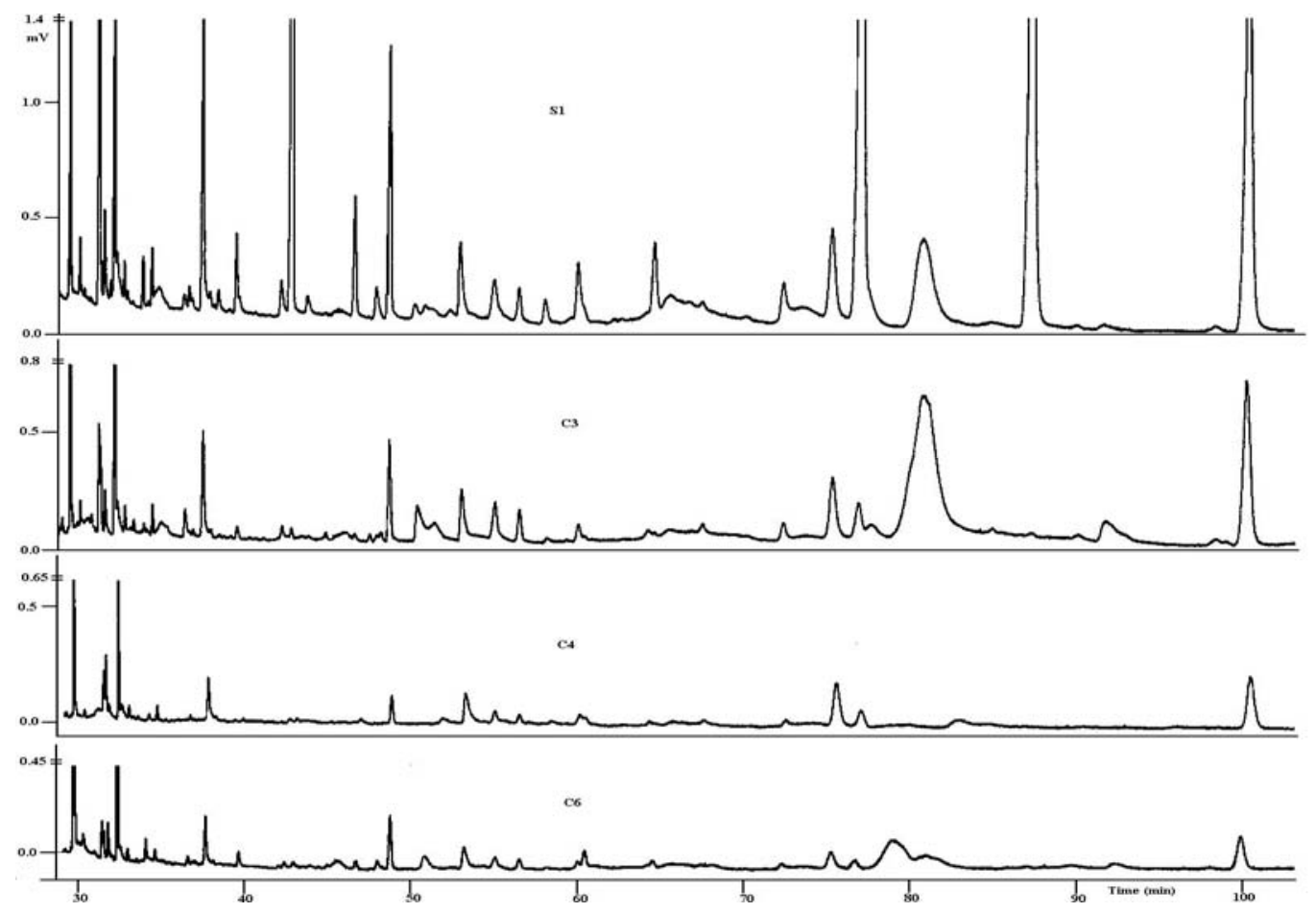

Figure 4. GC-FID chromatograms of the subcritical extract (S1) as compared with commercial extracts (C3,C4,C6).

Table II. Exhaustive extraction of polyphenols from wood, by use of repeated cycles, as a function of the ethanol content $(\% \mathrm{v} / \mathrm{v})$ of the extractant

\begin{tabular}{lccccc}
\hline $\begin{array}{l}\text { water/ethanol } \\
(\% \mathrm{v} / \mathrm{v})\end{array}$ & ${\text { cycle } 1^{*}}$ & ${\text { cycle } 2^{*}}$ & ${\text { cycle } 3^{*}}^{\text {cycle } 4^{*}}$ & $\begin{array}{c}\text { Total } \\
\text { extracted }\end{array}$ \\
\hline $90: 10$ & $125(62 \%)$ & $40(19 \%)$ & $23(11 \%)$ & $17(8 \%)$ & $205(100 \%)$ \\
$60: 40$ & $992(70 \%)$ & $258(19 \%)$ & $107(8 \%)$ & $36(3 \%)$ & $1393(100 \%)$ \\
\hline * total polyphenol index at $280 \mathrm{~nm}$
\end{tabular}




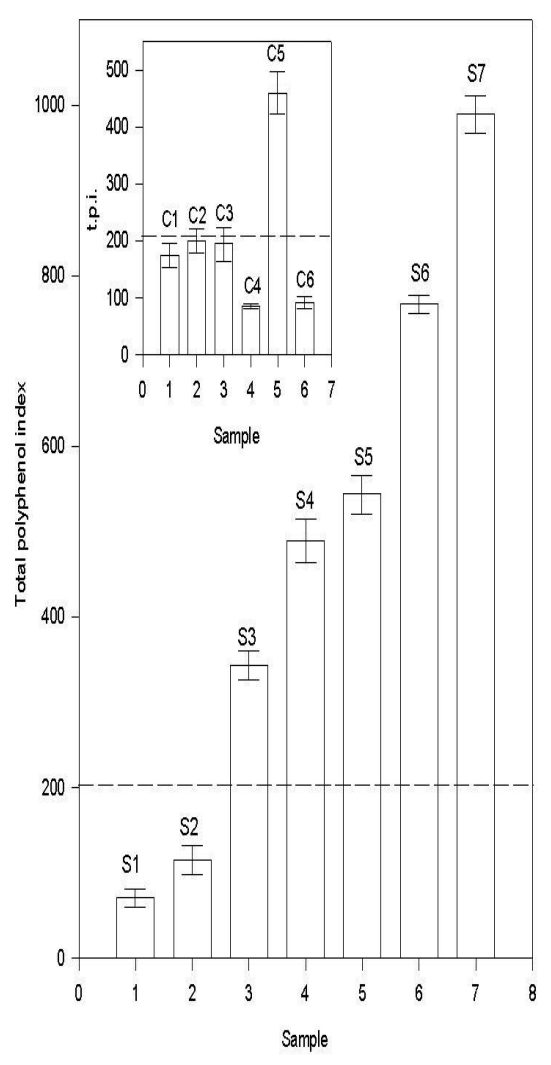

Figure 5. Detail of the t.p.i. from six commercial extracts (C1 to C6) and the t.p.i. of subcritical extracts obtained using different ethanolwater mixtures (S1: 5\%, S2: 10\%, S3: 20\%, S4: 30\%, S5: 40\%, S6: 50\%, S7: 60\%) as compared with the average value obtained from the commercial products (dotted line).

\section{Changes of the Extract Compo- sition}

The proposed extraction method allows alteration of the composition of the extract by changing extraction parameters such as temperature, extraction time and ethanol percentage in the extractant. These changes are unfeasible with the conventional methods [10].

\section{Conclusion}

As far as possible, the extracts obtained by use of subcritical water-ethanol mixtures were compared with commercial extracts due to the impossibility of obtaining in the laboratory extracts similar to those commercial. The policy of the industry hinders it to provide the authors with the detailed procedure. Only the final, concentrated extract obtained in the industry was supplied to the authors.

The extraction of wood compounds by use of subcritical ethanol-water mixtures presents a number of advantages as compared with conventional alternatives used in the industry, namely: shorter extraction times (60 min versus 47 hours required by Industrial methods); important saving of ethanol (extracts with only $20 \%$ ethanol surpasses the polyphenol content of commercial extracts); the obtained extracts are not inconsistent with the commercial ones; and the possibility of manipulating the composition by changing the extraction parameters (which allows the obtainment of extracts with different composition). The comparison of the GC-MS chromatograms from the extract and the commercial products shows that there is a $75 \%$ coincidence between the compounds found in both. 


\section{Acknowledgments}

The Spanish Comisión Interministerial de Ciencia y Tecnología (CICyT) is thanked for financial support (Project AGL2000-0321-P4-03).

\section{Bibliography}

(1) Marsal, F.; Sarre, C. Connaiss Vigne Vin 1987, 21, 71.

(2) Miller, D. P.; Howell, G.S.; Michaelis, C.S.; Dickmann, D.I. Am. J. Enol. Vitic. 1992, 43, 333.

(3) Nykanen, L. Am. J. Enol. Vitic. 1986, 37, 84.

(4) Chatonnet, P.; Boidron, J.N.; Pons, M. Connaiss Vigne Vin 1989, 23, 223.

(5) Chatonnet, P.; Boidron, J. N.; Pons, M. Sci. Aliments 1990, 10, 565.

(6) Nishimura, K.; Ohnishi, M.; Masuda, M.; Koga, K.; Matsuyama, R. Reactions of wood components during maturation, In Flavour of distilled beverages: origin and Development. Piggott, J.R. Ed., Ellis Horwood, Chichester, U.K., 1983, pp 241-255.

(7) Sefton, M.A.; Francis, I.L.; Pocock, K.F.; Williams, P.J. Sci. Aliments 1993, 13, 629.

(8) Guymon, J.F.; Crowell, E.A. Am. J. Enol. Vitic. 1972, 23, 114.

(9) Directiva 88/388/CEE de Consejo de 22 de junio de 1988. Diario Oficial de las Comunidades Europeas (L) No 184 del 15 de julio de 1988, p.61.

(10) Ullmann's Encyclopaedia of Industrial Chemistry, $5^{\text {th }}$ Ed., VCH
1988, Weinheim (West Germany), Vol A11.

(11) Soto-Ayala, R.; Luque de Castro, M.D. Food Chem. 2001, 75, 109.

(12) Gámiz-Gracia, L.; Luque de Castro, M.D. Talanta 2000, 51, 1179.

(13) Perry, R.H.; Green, D.W.; Mahoney, J.O. Perry's Chemical Engineers' Handbook, 6 ${ }^{\text {th }}$ Ed. Mc Graw Hill, New York 1984, Tome 1.

(14) Chatonnet, P.; Cutzach, I.; Pons, M.; Dubordieu, D. J. Agric. Food Chem. 1999, 47, 4310.

(15) Pérez-Coello, M.S.; Sanz, J.; Cabezudo, M.D. Chroma-togra-hia 1998, 47, 427.

(16) Pérez-Coello, M.S.; Sanz, J.; Cabezudo, M.D. Am. J. Enol. Vitic. 1999, 50, 162.

(17) Cutzach, I.; Chatonnet, P.; Henry, R.; Dubordieu, D. J. Agric. Food Chem. 1997, 45, 2217. 
